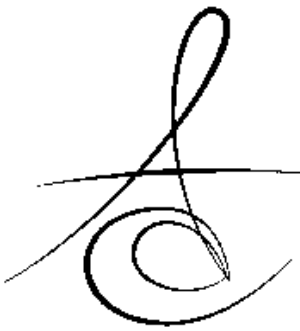

\title{
BİRİNCİ VE İKİNCİ MOLAR DİŞLERİN FURKASYON BÖLGELERİNDEKİ MİNE İNCİSİ PREVELANSININ İNCELENMESİ
}

\author{
PREVALENCE OF ENAMEL PEARLS IN FURCATION AREA OF FIRST AND \\ SECOND MOLAR TEETH
}

Dt. Denizhan KARA*

Arş. Gör. Dr. Fatma KARACAOĞLU*

Prof. Dr. Murat AKKAYA*

Makale Kodu/Article code: 3472

Makale Gönderilme tarihi: 20.07.2017

Kabul Tarihi: 10.01.2018

\section{öz}

Amaç: Bu çalışmanın amacı, birinci ve ikinci molar dişlerin furkasyon bölgelerindeki mine incisi prevelansını tespit ederek periodontal hastalıklarla ilişkisini ortaya koymaktır.

Gereç ve Yöntem: Çalışmada 682 erkek 936 kadın toplam 1618 hastadan elde edilen 2224 Konik Işınlı Bilgisayarlı Tomografi (KIBT) görüntüsü üzerinde alt ve üst çenelere ait toplam 3000 adet 1. ve 2. molar diş değerlendirilmiştir. Furkasyon bölgesinde mine incisi bulunan ve/veya varlığından şüphelenilen dişler 3 boyutlu olarak daha ayrıntılı incelenmiştir. Mine incilerinin şekil, lokasyon ve çap gibi özellikleri yine 3 boyutlu olarak incelenerek ortaya konmuştur.

Bulgular: Toplam 8 hastada 11 (\%0.3) adet mine incisi varlığı tespit edilmiştir. Maksiller birinci molar dişlerin \% 0.27'sinde, ikinci molar dişlerin \% 0.74'ünde furkasyon bölgesinde mine incisi tespit edilirken incelenen 1327 mandibular molar dişin hiç birinde mine incisi tespit edilmemiştir. Ek olarak, mine incisi tespit edilen dişlerde periodontal yıkım izlenmemiştir.

Sonuç: Çalışmamızda furkasyon bölgesinde yer alan mine incisi prevalansı \% 0.3 olarak tespit edilmiştir. Bununla birlikte mine incisi tespit edilen dişlerde periodontal yıkım izlenmemesi mine incisinin periodontitis oluşması için tek başına yeterli bir faktör olmadığını, periodontal hastalığın başlamasından çok ilerlemesini etkilediğini ortaya konmuştur.

Anahtar Sözcükler: Mine incisi, furkasyon bölgesi, periodontitis

\section{ABSTRACT}

Aim: The aim of this study is to identify the the prevalence of enamel pearls in the furcation areas of the first and second molar teeth and to reveal their association with periodontal disease.

Materials and Method: In this study, 2224 Cone Beam Computerized Tomography (CBCT) images were obtained from 1618 patients (963 female and 682 male) were evaluated. A total of 3000 maxillary and mandibular first and second molar teeth were examined. The teeth with enamel pearls or suspected enamel pearls in the furcation area were examined in more detail in 3-D images. In addition, enamel pearls features such as shape, location and diameter were evaluated in 3-D images.

Results: A total of 11 enamel pearl were detected in 8 patients ( 9 teeth). $0.27 \%$ of them were found in the maxillary first molar teeth and $0.74 \%$ in the maxillary second molar teeth. None of the 1327 mandibular molar teeth had enamel pearls. In addition, periodontal destruction was not observed in the tooth where enamel pear was detected.

Conclussion: In this study, the prevalence of enamel pearl in the furcation area was recorded as $0.3 \%$. However, the periodontal destruction was not detected in the tooth which the enamel pearl was detected. This suggests that the enamel pearls were not a sufficient factor to form periodontitis alone, but it affects the progression far beyond the onset of periodontal disease.

Keywords: Enamel pearl, furcation area, periodontitis

*Ankara Üniversitesi Diş Hekimliği Fakültesi Periodontoloji AD, Ankara. 


\section{GİRIŞ̧}

Periodontal hastalıklar, periodontopatojenlerin varlığı (subgingival plak biyofilm), lokal etkenler, konak yatkınlığı ve genetik faktörler gibi multifaktoriyel etkileşimlerin sonucu olarak ortaya çıkan enflamatuar hastalıklardır. Bakteriyel plak, periodontal hastalığın başlangıcı ve ilerlemesinde birincil neden olmasına rağmen, lokal çevresel faktörler önemli modifiye edici rol oynarlar ${ }^{1-2}$. Dişlerin kuron ve köklerinde meydana gelen, palatal oluklar, servikal mine projeksiyonları veya mine incileri gibi gelişimsel anomaliler, periodontal sağlığı olumsuz yönde etkileyen çevresel faktörler arasında yer alır ${ }^{3-7}$.

Köklerde görülen şekil anomalilerinden biri olan mine incileri, bağ dokusu ataçmanına girerek sadece hemidezmozal birleşime müsaade ettikleri için periodontitis nedeni olarak görülmüşlerdir. Ek olarak, bu tür oluşumların yapısı ve konumu, plağın mekanik olarak tutulmasına izin verir ve hem hastalar hem de hekimler tarafından etkili bir şekilde uzaklaştırılmasını engelleyerek periodontal hastalıklara yol açabilir ${ }^{6,8-10}$.

Mine incisi, dişlerin dış kök yüzeyine sıkıca yapışan, genellikle yuvarlak, beyaz, pürüzsüz ve cam benzeri mine yapısı olarak tarif edilmiştir ${ }^{4}$. Etiyolojisi halen belirsiz olmakla birlikte kabul edilebilir en iyi teori, incinin, kök gelişimi sırasında kök yüzeyine yapışmış olan Hertwing epitel kök kılıf hücrelerinin lokalize gelişimsel aktivitesi nedeniyle oluştuğu teorisidir $^{5,11,12}$. Genellikle daimi dişlenmede görülen mine incileri süt dişlenme döneminde de görülebilir ${ }^{13}$. Klinik olarak tanımlanabilir mine incilerinin $0.3-4 \mathrm{~mm}$ boyutunda ve ortalama $0.96 \pm 0.43 \mathrm{~mm}$ çapında olduğu bildirilmiştir ${ }^{5}$. Mine incileri, maksiller molar dişlerin mezial ve distal yüzeylerinde ve daha az olarak mandibular molar dişlerin bukkal ve lingual yüzeylerinde görülür. Genel olarak yerleşim yerleri furkasyon bölgesi ya da kök oluğudur ${ }^{14}$.

Mine incisi gibi kök yüzey anomalileri genellikle radyolojik değerlendirme olmaksızın tespit edilemezler. Günümüze kadar mine incileri in vivo ve ex vivo olarak konvansiyonel radyografi ${ }^{6,13,14}$ ve konik ışınlı bilgisayarlı tomografi (KIBT) $)^{15,16}$ kullanılarak değerlendirilmiştir. Bununla birlikte son on yılda mikro-BT, diş sert dokularının üç boyutlu değerlendirilmesi için invaziv olmayan tekrarlanabilir bir yöntem ${ }^{8,17}$ olarak önem kazanmıştır.

Çoğu zaman semptomsuz olan mine incilerinin klinik olarak tespiti ve takip edilmesi oluşabilecek periodontal yıkımı engellemek açısından önemlidir. Etkilenen molar dişlerde mine incisinin bırakılmasının ya da kaldırımasının periodontal iyileşme cevabında farklılık yaratıp yaratmadığı ise bilinmemektedir. Ek olarak, periodontal hastalıklara yol açabileceği düşünülen servikal mine incilerine müdahale imkanı varken furkasyon bölgelerindekilere müdahale imkanı çok daha sınırlıdır ve bu nedenle herhangi bir sorun oluştuğunda ilgili dişin çekimi gerekebilir. Bu çalışmanın amacl, furkasyon bölgesindeki mine incisi prevalansını belirleyerek diş hekimlerinin karşılaşabileceği sorunun boyutlarını ortaya koymaktır.

\section{GEREÇ VE YÖNTEM}

Bu çalışmada özel bir görüntüleme merkezine (Dentistomo Görüntüleme Merkezi) 18.02.2012 02.04.2014 tarihleri arasında herhangi bir sebepten KIBT çektirmek üzere başvuran hastalardan elde edilen KIBT görüntüleri incelenmiştir. 682 erkek 936 kadın toplam 1618 hastadan elde edilen ve 1 . ve/veya 2. molar dişin görüntüye girdiği 2224 KIBT görüntüsü çalışmaya dahil edilmiştir. Kron, metalik dolgular, kanal tedavisi gibi görüntüyü bozan veya 1 . ve/veya 2 . molar dişin furkasyon bölgesinin incelenmesini engelleyen durumlarda tomografiler çalışma dışında tutulmuştur. Toplamda alt ve üst çenelere ait toplam 3000 adet 1 . ve 2. molar diş mine incisi varlığı açısından değerlendirilmiştir. Çalışma Ankara Üniversitesi Diş Hekimliği Fakültesi Etik Kurulu tarafından onaylanmıştır (13/07/2016 13-17).

Çalışmada incelenen bütün tomografik görüntüler aynı KIBT (Kodak Carestream 9300 C Select, Fransa) cihazı ile elde edilmiştir. Tomografiler tek bir gözlemci tarafından karanlık bir odada incelenmiştir. Göz yorgunluğu nedeniyle mine incisi varlığının fark edilememesinin önlenmesi amacıyla değerlendirme yarım saat tomografi inceleme beş dakika dinlenme süresi şeklinde yapılmıştır.

Bütün dişler 1'mmlik kesitsel görüntülerde CS 3D imaging programı ile incelenmiştir. Furkasyon bölgesinde mine incisi bulunan ve/veya varlığından şüphelenilen dişler 3 boyutlu olarak daha ayrıntılı incelenmiş, bu dişlerde periodontal yıkım olup olmadığı da kaydedilmiştir. Mine incilerinin şekil, lokasyon ve çap gibi özellikleri de yine 3 boyutlu olarak incelenerek kaydedilmiştir. 


\section{BULGULAR}

Çalışmamıza 1618 hastaya ait (682 erkek, 936 kadın) KIBT görüntüsü dahil edilmiş ve toplamda 3000 adet 1 . ve 2. molar diş incelenmiştir. Bu dişlerin çenelere ve dişlere göre sınıflandırılması Tablo 1'de verilmiştir.

Tablo 1. İncelenen dişler ve bulundukları bölgelere göre sınıflandırılması

\begin{tabular}{|l|c|c|c|l|}
\hline & & Maksilla & Mandibula & Toplam \\
\hline 1. & Molar & 731 & 483 & 1214 \\
\hline Toplam & Molar & 942 & 844 & 1786 \\
\hline & & 1673 & 1327 & 3000 \\
\hline
\end{tabular}

Toplam 8 hastanın (2 erkek, 6 kadın) 9 adet 1. molar ve/veya 2. molar dişinin furkasyon bölgesinde 11 adet mine incisi tespit edilmiştir. Bir hastanın sağ üst ikinci molar dişinde bir tane, sol üst ikinci molar dişinde iki tane mine incisine rastlanılırken; başka bir hastanın sağ üst birinci molar dişinde iki tane mine incisine rastlanılmıştır. Altı hastanın ise birer dişinde birer adet mine incisi bulunmuştur. Mine incilerinin bulundukları dişler ve dağılımı Tablo 2' de gösterilmiştir.

Tablo 2. Mine incisi saptanan dişlerin bulundukları bölgelere ve dişlere göre sınıflandırılması

\begin{tabular}{|l|l|l|c|c|}
\hline & & Maksilla & Mandibula & Toplam \\
\hline 1. & Molar & $2(\% 0.27)$ & $0(\% 0)$ & $2(\% 0.165$ \\
\hline 2. & Molar & $7(\% 0.74)$ & $0(\% 0)$ & $7(\% 0.39)$ \\
\hline & Toplam & $9(\% 0.54)$ & $0(\% 0)$ & $9(\% 0.3)$ \\
\hline
\end{tabular}

Tablo 3. Mine incilerinin çaplarına göre sınıflandıııması

\begin{tabular}{|c|c|}
\hline Mine İncisi Çapı & Mine İncisi Adedi \\
\hline $0-0.5 \mathrm{~mm}$ & 1 \\
\hline $0.6-1 \mathrm{~mm}$ & 5 \\
\hline $1.1-1.5 \mathrm{~mm}$ & 3 \\
\hline $1.6-2 \mathrm{~mm}$ & 2 \\
\hline
\end{tabular}

Çalışmamızda 3000 1. ve 2. molar dişin 9'unda (\% 0.3) furkasyon bölgesinde mine incisi görülmüş, erkeklerin \% $0.29^{\prime}$ unda, kadınların \% $0.64^{\prime}$ ünde furkasyon bölgesinde mine incisi tespit edilmiştir. Ayrıca maksiller ikinci molar dişlerde birinci molar dişlere oranla 3.5 kat daha fazla mine incisi tespit edilmiştir. İncelenen 1327 mandibular molar dişte hiç mine incisine rastlanılmaması da önemli bir bulgudur. En yüksek oran \% 0.74 ile maksiller ikinci molar dişlerde bulunmuştur.
Tespit edilen mine incilerinin 1 tanesinin su damlası şeklinde, 10 tanesinin ise küre şeklinde olduğu görülmüştür. Küre şeklindeki incilerin çapları $0.3 \mathrm{~mm}$ ile $1.7 \mathrm{~mm}$ arasında değişiklik göstermektedir (ortalama $1.12 \mathrm{~mm}$ ) (Tablo 3). Su damlası şeklindeki mine incisinin uzunluğu $1.5 \mathrm{~mm}$ genişliği ise $0.7 \mathrm{~mm}$ olarak ölçülmüştür.

Mine incisi saptanan dişlerin hiç birinde periodontal yıkım izlenmemiştir

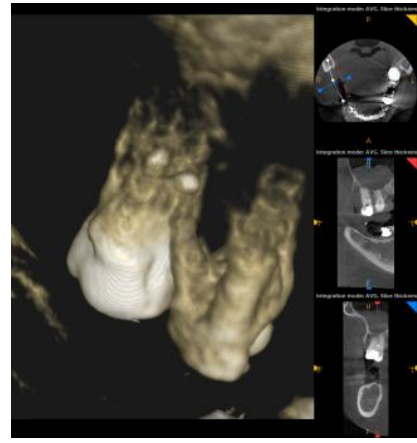

Resim 1. KIBT görüntüsünde mine incisi

\section{TARTIŞMA}

Ektopik mine genellikle azı dişlerde ileri derecede lokalize periodontal hasar ile ilişkilidir ve hem furkasyon bölgesinde yer alan mine incileri hem de servikal mine projeksiyonları ilave ataçman kaybına neden olabilir ${ }^{18}$. Enflamatuar infiltrasyon mine incisine ulaşırsa, mine incisi anatomisi sebebiyle mekanik plak retansiyonuna izin verdiği ve bununla birlikte plağın mekanik olarak uzaklaştırılmasını güçleştirdiği için, periodontal doku kaybı hızlanabilir ${ }^{5}$. Lima ve $a^{19}{ }^{19}$ mine incisinin servikal çizgisi ile furkasyon tepesi arasındaki mesafe ne kadar küçük olursa, minör mine incisi varlığında periodontal hastalık meydana gelme oranının o kadar yüksek olacağını bildirmiştir. Dolayısıyla yalnızca mine incisi boyutu değil furkasyon bölgesi ile topografik ilişkisi de periodontal hastalığa katkıda bulunan bir faktör olabilir20. Buradan yola çıkarak çalışmamızda birinci ve ikinci molar dişlerin furkasyon bölgesinde yer alan mine incisi prevalansı değerlendirilmiştir.

Çalışmamızda mine incisi prevalansını değerlendirmek ve lezyonun kapsamını ve çevresindeki yapılar üzerindeki etkisini belirlemek için sınırlı alandaki KIBT görüntüsü taranmıştır. Mine incisi tanısı konvansiyonel radyografi ile konulabilmesine rağmen, kompozit mine incilerinin yoğunluğu, yapısı ve konumu yüksek

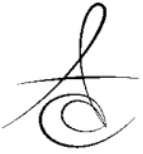


çözünürlüklü volümetrik bilgisayarlı tomografi ile tanımlanabilir. Ek olarak bu yöntemin, gelecekteki periodontal kemik kaybı riskini prognostik olarak değerlendirmek için, mine incisi ve alveol kret veya furkasyon alanları arasındaki mesafenin değerlendirilmesine de yardımcı olacağı bildirilmiştir ${ }^{16}$. Çalışmamızda kesitsel görüntülerde furkasyonun tam ortasındaymış gibi görülen mine incilerinin aslında mezialpalatinal ya da distal-palatinal kökler arasında bulunduğu 3 boyutlu tomografi görüntülerinden anlaşılmışır. Bu durum mine incisinin lokalizasyonunun belirlenmesinde tomografik görüntülemenin avantajını açıkça ortaya koymaktadır. Ayrıca, sınırı alandaki KIBT görüntüsünün radyasyon dozu, iki periapikal radyografinin radyasyon dozuna benzerdir ve komplike diş çekimi ve implant yerleştirilmesi gibi durumlarda dahi bir çok geleneksel yöntemle kıyaslandığında doz tasarrufu sağlayabilir ${ }^{16}$.

Üç bin adet molar dişi incelediğimiz çalışmamızda mine incisi prevalansı $\% 0.3$ olarak bulunmuştur. Farklı popülasyonlarda makroskopik olarak tespit edilebilir mine incilerinin prevalansı \%0-23.3 arasında değişkenlik göstermektedir ${ }^{11}$. Risnes ve Chrcanovic çekilmiş dişlerde yaptıkları çalışmalarda molar dişlerde mine incisi prevalansını sırasıyla $\% 2.28$ ve $\% 1.71$ olarak bildirmiştir ${ }^{11,21}$. Akgül ve ark. ise mine incisi varlığını KIBT ile değerlendirdikleri in vivo çalışmada molar dişlerin \%0.83 ünde en az 1 tane mine incisi tespit etmiş̧ir ${ }^{15}$. Çalışmamı sonunda bulduğumuz mine incisi prevalansı önceki çalışmalara göre biraz daha düşük olmakla birlikte prevalanstaki değişkenlik çalışma popülasyonlarındaki etnik ve metodolojik farklılıklar ile ilişkili olabilir.

Maksiller premolar, kanin ve keser dişlerin köklerinde mine incisi meydana geldiğini gösteren az sayıda çalışma olmasına rağmen ${ }^{3}$, genel olarak mine incilerinin en çok maksiler molarların ve bunu takiben mandibular molarların köklerinde meydana geldiği kabul edilmektedir ${ }^{3,11,15,21}$. Çalışmamızda 1673 maksiller molar ve 1327 mandibular diş incelenmiş olup mine incisi varlı̆ı sadece maksiler molar dişlerde saptanmıştır ki önceki çalışmalarla tutarıdır. Mine incilerinin, molar dişlerin furkasyon bölgesi ve kök yapısı içindeki oluklara da belirgin bir eğilimi olduğu ve maksiller molar dişlerin kökleri üzerinde oluştuğunda, sıklıkla disto-bukkal ile palatal kökler arasında görüldüğü bildirilmiştir ${ }^{3,11,21}$. Çalışmamızda 9 adet maksiler molar dişte saptanan 11 mine incisinin 4 tanesinin mezial kök ile palatinal kök arasında, 3 tanesinin distal kök ile palatinal kök arasında, 2 tanesinin 3 kökün tam ortasında, 2 tanesinin ise distal ve palatinal köklerin distal yüzeyinde olduğu tespit edilmiştir.

Çalışmamızda tespit edilen 11 mine incisinin çapları 0.4-1.7 mm arasında değişmekte olup ortalama $1.02 \mathrm{~mm}$ olarak bulunmuştur. Risnes ${ }^{11}, 8854$ molar dişi değerlendirdiği çalışmada mine incilerinin çaplarının 0,3 mm'den 4 mm'ye kadar değişen büyüklükte olduğunu göstermiştir. Ancak incelenen diş sayısı bizim çalışmamızda incelenenin yaklaşık üç katıdır. Loh $^{23}$ yaptığı çalışmada mine incilerin \% 57'sinin çapının 1.0 mm'den 1.9 mm'ye kadar değiştiğini rapor etmiştir. Sutalo ve arkadaşları ise ortalama mine incisi çapının $1.7 \mathrm{~mm}$ olduğunu bildirmiştir ${ }^{24}$. Sonuçlarımı bu çalışmaların sonuçları ile uyumludur.

Literatürde mine incisiyle ilişkili periodontal lezyonları gösteren vaka raporları mevcut ${ }^{4-7,16}$ olmasına rağmen bizim çalışmamızda mine incisi bulunan dişlerde periodontal kayıp izlenmemiştir. Bununla birlikte yayınların pek çoğunda periodontal lezyon meydana gelen dişlerin mine incisi servikal bölgede veya kök yüzeyinde yer almaktadır. Çalışmamızın sonuçları furkasyon bölgesinde yer alan mine incilerinin periodontitisin oluşması için tek başına yeterli bir faktör olmadığını, periodontal hastalığın başlamasından çok ilerlemesini etkilediğini ortaya konmuştur.

\section{SONUÇLAR}

Çalışmamızda furkasyon bölgesinde yer alan mine incisi prevalansı $\% 0.3$ olarak kaydedilmiştir. Bununla birlikte mine incisi tespit edilen dişlerde periodontal yıkım izlenmemesi mine incisinin periodontitisin oluşması için tek başına yeterli bir faktör olmadığını, periodontal hastalığın başlamasından çok ilerlemesini etkilediğini ortaya konmuştur.

(Bu makale yazarlarından hiçbirinin makalede bahsi geçen konu ve malzemeyle ilgili herhangi bir ilişkisi, bağlantısı veya parasal çıkar durumu söz konusu değildir.)

Denizhan KARA: ORCID ID: 0000- 0001-7057-5190

Fatma KARACAOĞLU: ORCID ID: 0000-0003-0122-203

Murat AKKAYA: ORCID ID: 0000-0002-3211-6572

\section{KAYNAKLAR}

1. Ertugrul AS, Tekin Y, Dikilitas A, Bozoglan A, Sahin $\mathrm{H}$, Alparslan NZ. Determining the relationship between angle of roots, crown furcation roof angle, and furcation defects using cone beam 
computerized tomography. J Dent Fac Atatürk Uni 2013;21:9-45.

2. Matthews DC, Tabesh M. Detection of localized tooth-related factors that predispose to periodontal infections. Periodontol 2000 2004;34:136-50.

3. Moskow BS, Canut PM. Studies on root enamel (2). Enamel pearls. A rewiev of their morphology, localization, nomenclature, occurence, clsassification, histogenesis and incidence. J Clin Periodontol 1990;17275-81.

4. Romeo U, Palaia G, Botti R, Nardi A, del Vecchio A, Tenore G. Enamel Pearls as a predisposing factor to localized Periodontitis. Quintessence Int 2011;42: 69-71.

5. Goldstein AR. Enamel pearls as contributing factor in periodontal breakdown. J Am Dent Assoc 1979;99:210-1.

6. Sharma S, Malhotra S, Baliga V, Hans M. Enamel pearl on an unusual location associated with localized periodontal disease: A clinical report. J Indian Soc Periodontol 2013; 17: 796-800.

7. Risnes S, Segura J, Casado A, Jimenez-Rubio A. Enamel pearls and cervical enamel projections on 2 maxillary molars with localized periodontal disease. Oral Surg Oral Med Oral Pathol Oral Radiol Endod 2000; 89: 493-7.

8. Versiani MA, Cristescu RC, Saquy PC, Pecora JD, Sousa-Neto MD. Enamel pearls in permanent dentition: case report and micro-CT evaluation. Dentomaxillofac Radiolq 2013;42:1-7.

9. Skinner MA, Shiloah J. The role of enamel pearls in localized severe Periodontitis. Quintessence Int 1989; 20: 181-3.

10. Croft LK. Periodontal abscess from enamel pearl. Oral Surg Oral Med Oral Pathol 1971; 32: 154.

11. Risnes S. The prevalence, location and size of enamle pearls on human molars. Scand J Dent Res 1974; 82: 403-12.

12. Anderson P, Elliott JC, Bose U, Jones SJ. A comparision of the mineral content of enamel and dentine in human premolars and enamel pearls measured by X-ray microtomography. Arc Oral Biol 1996; 41: 281-90.

13. Kupietzky A, Rozenfarb N. Enamel pearls in the primary dentition: report of two cases. ASDC J Dent Child 1993; 60: 63-6.

14. Worth H. Odontomes. In: Principles and practice of oral radiologic interpretation. Chicago, IL: Year
Book, 1963, pp 424-6.

15. Akgül N, Caglayan F, Durna N, Sümbüllü MA, Akgül HM, Durna D. Evaluation of enamel pearls by cone-beam computed tomography (CBCT). Med Oral Pathol Oral Cir Bucal 2012;17: e218-e22.

16. Saini T, Ogunleye A, Levering N, Norton NS, Edwards $P$. Multiple enamel pearls in two siblings detected by volumetric computed tomography. Dentomaxillofac Radiol 2008;37:240-4.

17. Versiani MA, Pecora JD, Sousa-Neto MD. The anatomy of two-rooted mandibular canines determined using micro-computed tomography. Int Endod J 2011;44: 682-7.

18. Hou GL, Tsai CC. Cervical enamel projection and intermediate bifurcational ridge correlated with molar furcation involvements. J Periodontol 1997; 68: 687-93.

19. Lima AF, Nascimento A, Hebling E. Projection of cervical enamel and its relations to bifurcation. Odonto Mod 1991; 18: 9-15.

20. Darwazeh A, Hamasha AA. Radiographic evidence of enamel pearls in Jordanian dental patients. Oral Surg Oral Med Oral Pathol Oral Radiol Endod 2000; 89: $255-8$.

21. Chrcanovic BR, Abreu MH, Custodio AL. Prevalence of enamel pearls in teeth from a human teeth bank. J Oral Sci 2010; 52: 257-60.

22. AAE/AAOMR. Use of cone-beam computed tomography in endodontics Joint Position Statement of the American Academy of Oral and Maxillofacial Radiology. Oral Surg Oral Med Oral Pathol Oral Radiol Endod 2011; 111: 234-7.

23. Loh HS. A local study on enamel pearls. Singapore Dent J 1980; 5: 55-9.

24. Sutalo J, Ciglar I, Njemirovskij V. Incidence of enamel pearls in our population. Acta Stomatol Croat 1986; 20: 123-9

\section{Yazışma Adresi}

Dt. Denizhan KARA

Ankara Üniversitesi Diş Hekimliği Fakültesi

Periodontoloji A.D. 06500 Çankaya, Ankara.

Telefon : (0312)2965685

Fax no: (0312)2123954

e-posta: dtdenizhankara@gmail.com 